\title{
Amplitude regeneration of RZ-DPSK signals in single-pump fiber-optic parametric amplifiers
}

Peucheret, Christophe; Lorenzen, Michael Rodas; Seoane, Jorge; Noordegraaf, Danny; Nielsen, Carsten Vandel; Grüner-Nielsen, Lars; Rottwitt, Karsten

Published in:

I E E E Photonics Technology Letters

Link to article, DOI:

10.1109/LPT.2009.2019968

Publication date:

2009

Document Version

Publisher's PDF, also known as Version of record

Link back to DTU Orbit

Citation (APA):

Peucheret, C., Lorenzen, M. R., Seoane, J., Noordegraaf, D., Nielsen, C. V., Grüner-Nielsen, L., \& Rottwitt, K. (2009). Amplitude regeneration of RZ-DPSK signals in single-pump fiber-optic parametric amplifiers. I $E E E$ Photonics Technology Letters, 21(13), 872-874. https://doi.org/10.1109/LPT.2009.2019968

\section{General rights}

Copyright and moral rights for the publications made accessible in the public portal are retained by the authors and/or other copyright owners and it is a condition of accessing publications that users recognise and abide by the legal requirements associated with these rights.

- Users may download and print one copy of any publication from the public portal for the purpose of private study or research.

- You may not further distribute the material or use it for any profit-making activity or commercial gain

- You may freely distribute the URL identifying the publication in the public portal 


\title{
Amplitude Regeneration of RZ-DPSK Signals in Single-Pump Fiber-Optic Parametric Amplifiers
}

\author{
Christophe Peucheret, Michael Lorenzen, Jorge Seoane, Danny Noordegraaf, Carsten Vandel Nielsen,
} Lars Grüner-Nielsen, and Karsten Rottwitt

\begin{abstract}
The input power tolerance of a single-pump fiber-optic parametric amplifier (FOPA) is experimentally shown to be enhanced for return-to-zero differential phase-shift keying (RZ-DPSK) modulation compared to RZ ON-OFF keying modulation at $40 \mathrm{~Gb} / \mathrm{s}$. The improved nonlinear tolerance is exploited to demonstrate amplitude regeneration of a distorted RZ-DPSK signal in a gain-saturated FOPA. An optical signal-to-noise ratio penalty of $3.5 \mathrm{~dB}$ after amplitude distortion is shown to be reduced to $0.2 \mathrm{~dB}$ after the FOPA, thus clearly demonstrating the regenerative nature of saturated FOPAs for RZ-DPSK modulation.
\end{abstract}

Index Terms-Differential phase-shift keying (DPSK), fiber-optic parametric amplifier (FOPA), optical regeneration.

\section{INTRODUCTION}

$\mathbf{N}$ ONLINEAR phase noise (NPN) is one of the most severe impairments in return-to-zero differential phase-shift keying (RZ-DPSK) transmission [1]. Limiting the intensity fluctuations of the signal has been shown to reduce the accumulation of NPN, hence the need for all-optical intensity fluctuation reduction techniques that are furthermore transparent to the phase [2]. Recently, a number of techniques addressing this issue have been investigated. Those include the use of a modified nonlinear optical loop mirror with asymmetric gain profile between the counterpropagating fields [3], saturation of four-wave mixing (FWM) [2], [4], phase sensitive amplification [5], or various schemes involving phase-to-intensity modulation conversion, intensity regeneration, and phase remodulation [6].

Gain saturation in a fiber-optic parametric amplifier (FOPA) has been shown to enable intensity equalization of $\mathrm{ON}-\mathrm{OFF}$ keying (OOK) signals [7]. Since the process is phase-preserving and furthermore relies on the ultrafast Kerr effect in highly nonlinear optical fibers (HNLFs), it is also expected to be suitable for amplitude regeneration of high-speed RZ-DPSK signals. Indeed, signal saturation induced by pump depletion due to FWM has been investigated numerically for DPSK signals [2]

Manuscript received October 10, 2008; revised February 24, 2009. First published April 14, 2009; current version published June 10, 2009. This work was supported in part by the European Office of Aerospace Research and Development under Grant 063094.

C. Peucheret, J. Seoane, D. Noordegraaf, and K. Rottwitt are with DTU Fotonik, Department of Photonics Engineering, Technical University of Denmark, DK-2800 Kgs. Lyngby, Denmark (e-mail: cpeu@ fotonik.dtu.dk; jseo@ fotonik. dtu.dk; dano@fotonik.dtu.dk; karo@fotonik.dtu.dk).

M. Lorenzen and C. V. Nielsen were with DTU Fotonik, DK-2800 Kgs. Lyngby, Denmark.

L. Grüner-Nielsen is with OFS Fitel Denmark ApS, DK-2605 Brøndby, Denmark (e-mail: gruner@ofsoptics.com).

Color versions of one or more of the figures in this letter are available online at http://ieeexplore.ieee.org.

Digital Object Identifier 10.1109/LPT.2009.2019968

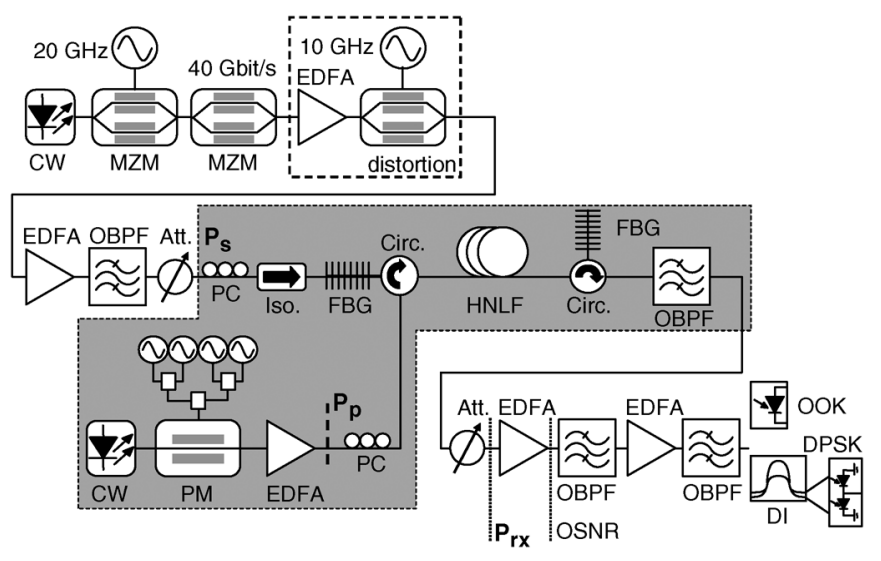

Fig. 1. Experimental setup. Att: attenuator; PC: polarization controller; Iso.: isolator; Circ: circulator; PM: phase modulator. The other acronyms are defined in the text.

and preliminary experimental results based on amplitude histograms have also been reported in the nonamplifying regime and for low duty cycle pulses [4], [8]. A recent experimental analysis of constellation diagrams in a saturated FOPA has clearly demonstrated amplitude regeneration, however, at the expense of some added phase noise [9]. Consequently, unambiguous bit-error-ratio (BER) measurements are required in order to fully assess the regenerative nature of saturated FOPAs for RZ-DPSK signals.

In this work, it is shown experimentally that the input power tolerance of a single pump (amplifying) FOPA can be significantly enhanced for RZ-DPSK modulation as compared to RZ-OOK. This effect is furthermore exploited to demonstrate successful amplitude regeneration of a highly distorted $40-\mathrm{Gb} / \mathrm{s}$ RZ-DPSK signal in an FOPA with over 20-dB small signal gain. This letter complements the results recently presented in [10].

\section{EXPERIMENTAL SETUP}

The experimental setup is depicted in Fig. 1. A 40-Gb/s $33 \%$ RZ-OOK or RZ-DPSK signal is generated from a continuous-wave (CW) laser using a Mach-Zehnder modulator (MZM) pulse carver driven by a $20-\mathrm{GHz}$ sinusoidal signal followed by a data modulator driven with a $2^{31}-1$ pseudorandom binary sequence (PRBS). The modulation format is selected by a proper choice of the bias and peak-to-peak voltage of the data signal applied to the second MZM. The signal input power to the FOPA is then adjusted using an erbium-doped fiber amplifier (EDFA) followed by an optical bandpass filter (OBPF) and a variable attenuator. The pump signal is derived from a CW laser amplified up to $30.5 \mathrm{dBm}$ in an EDFA. In order 

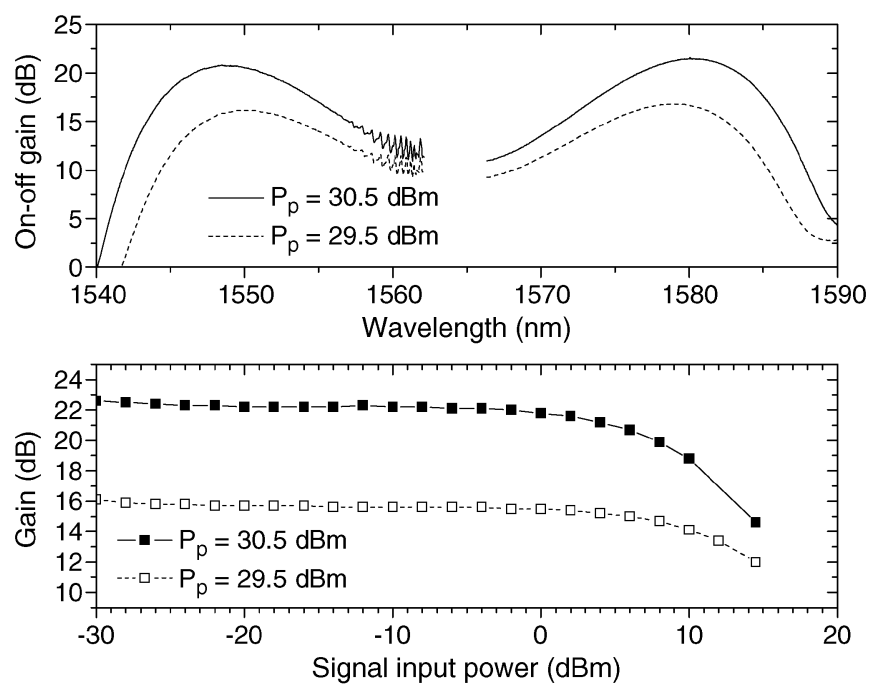

Fig. 2. FOPA ON-OFF gain spectrum (top) and gain as a function of signal input power (bottom).

to suppress stimulated Brillouin scattering (SBS), the pump is phase modulated using four sinusoidal tones at 123,600, 1000, and $2350 \mathrm{MHz}$. The SBS threshold of the fiber, estimated at $17 \mathrm{dBm}$ without phase modulation, could be increased beyond $28 \mathrm{dBm}$ using the four modulating tones. Signal and pump are coupled into the 500-m-long highly nonlinear fiber using a fiber Bragg grating (FBG) and a circulator. This coupling scheme also enables reduction of the amplified spontaneous emission (ASE) noise generated in the high-power EDFA used to amplify the output of the pump laser. The HNLF has zero dispersion at $1560.5 \mathrm{~nm}$, a dispersion slope equal to $0.015 \mathrm{ps} /\left(\mathrm{nm}^{2} \cdot \mathrm{km}\right)$, an attenuation of $0.74 \mathrm{~dB} / \mathrm{km}$, and a nonlinear coefficient of $11.5 \mathrm{~W}^{-1} \cdot \mathrm{km}^{-1}$. At the HNLF output, the signal wavelength is selected using another FBG followed by an OBPF, with full-width half-maximum bandwidths of 1.4 and $1.3 \mathrm{~nm}$, respectively. The signal is then input to a receiver consisting of an optical preamplifier and a $40-\mathrm{GHz}$ photodiode (in the case of $\mathrm{OOK}$ ) or a 1-bit delay interferometer (DI) followed by a balanced detector (in the case of DPSK).

\section{Results AND Discussion}

The FOPA was characterized for a pump wavelength of $1564.1 \mathrm{~nm}$ and a CW signal, as shown in Fig. 2. The ON-OFF gain, defined as the ratio of the signal power at the HNLF output with the pump turned ON to the same quantity with the pump turned OFF, peaks around 1549.5 and $1548.5 \mathrm{~nm}$ for 29.5 - and $30.5-\mathrm{dBm}$ pump power, respectively. Due to the availability of an FBG at that wavelength, the signal was tuned to $1546 \mathrm{~nm}$ in the experiments. The FOPA exhibits clear saturation behavior with small signal gains of 16 and $22 \mathrm{~dB}$ and input saturation powers of 13 and $9.5 \mathrm{dBm}$ for 29.5- and 30.5- $\mathrm{dBm}$ pump power, respectively. Once saturation, a prerequisite for amplitude regeneration, is clearly established under static operation, the FOPA performance can be evaluated for modulated signals.

The optical signal-to-noise ratio (OSNR) penalty compared to back-to-back was measured (in a $0.1 \mathrm{~nm}$ bandwidth) at a BER of $10^{-9}$ as a function of signal input power to the FOPA for both RZ-OOK and RZ-DPSK modulation. The limitation of the performance of the amplifier by poor OSNR and nonlinearities at low and high input power, respectively, is clearly observed
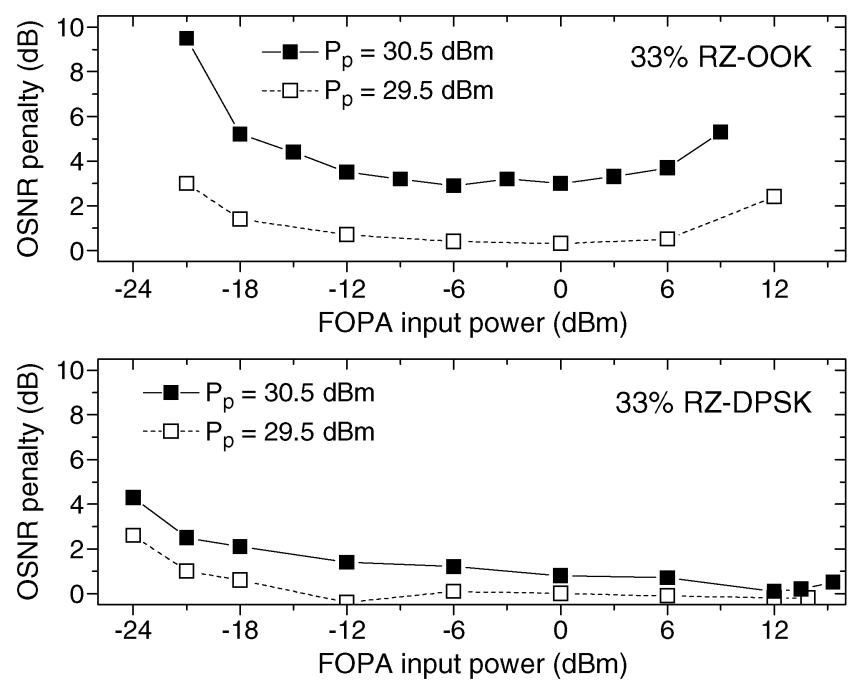

Fig. 3. OSNR penalty as a function of FOPA input signal power for RZ-OOK (top) and RZ-DPSK (bottom) modulation.
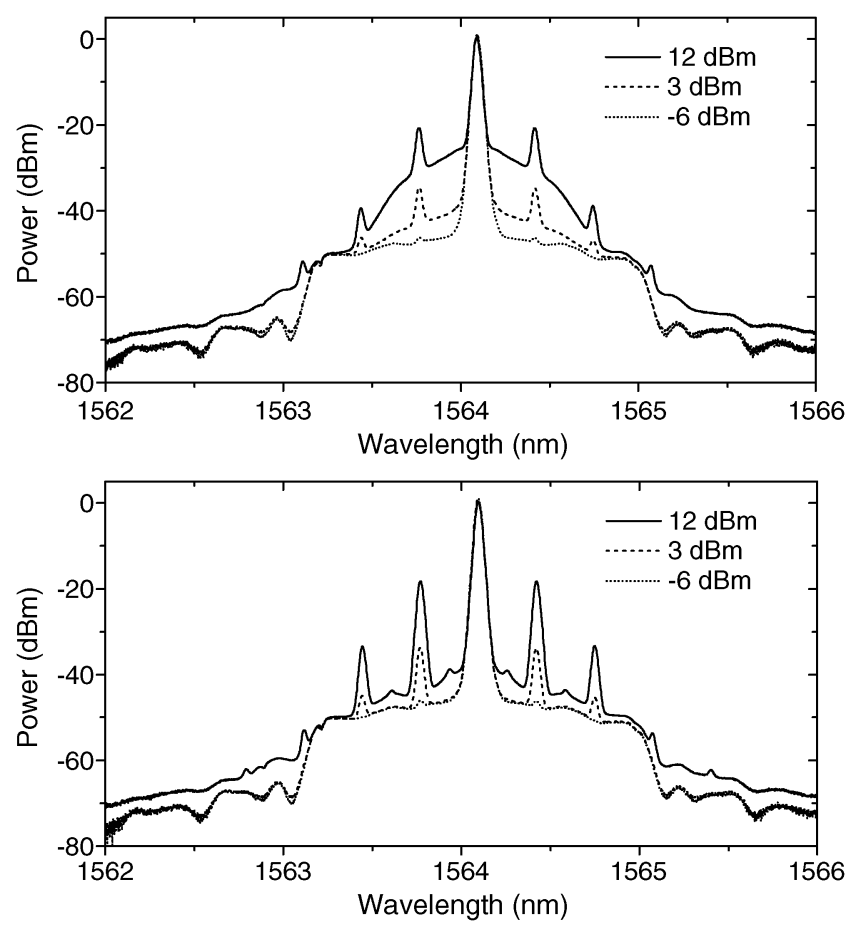

Fig. 4. Spectra in the vicinity of the pump wavelength in the case of RZ-OOK (top) and RZ-DPSK (bottom) modulation.

in Fig. 3 in the case of RZ-OOK. The higher penalty observed for $30.5-\mathrm{dBm}$ pump power is due to enhanced self-phase modulation (SPM) at high path average power through the HNLF. However, the inherent resilience of RZ-DPSK to SPM, which is due to its periodic power envelope, results in lower penalty and larger high input power tolerance than for RZ-OOK. Such an observation is in line with recent studies dealing with double pump FOPAs [11]. The onset of nonlinear degradation had actually not been reached with the maximum value of signal power that was available in our experiment $(15 \mathrm{dBm})$.

Fig. 4 compares the spectra in the vicinity of the pump wavelength for RZ-OOK and RZ-DPSK and for signal input power to the FOPA of $-6,3$, and $12 \mathrm{dBm}$. The effect of cross-phase 

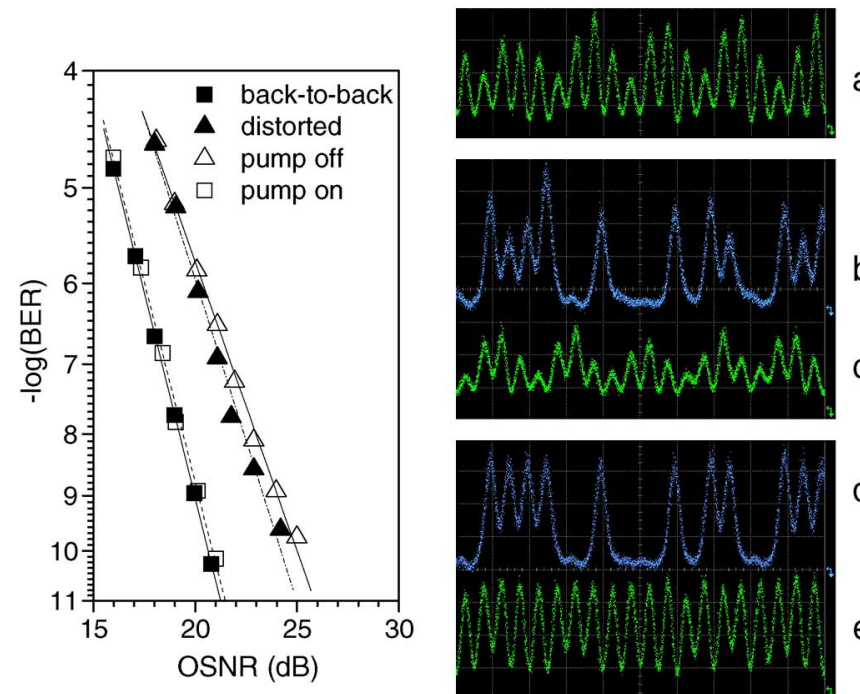

a
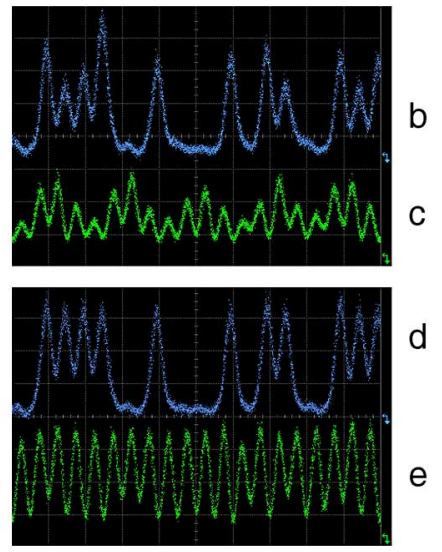

Fig. 5. BER curves and patterns for RZ-DPSK (a) after distortion; (b), (c) at FOPA output with pump OFF; (d), (e) at FOPA output with pump ON. (a), (c), and (e) correspond to RZ-DPSK intensity waveforms, while (b) and (d) are the corresponding waveforms after the DI and single-ended detection.
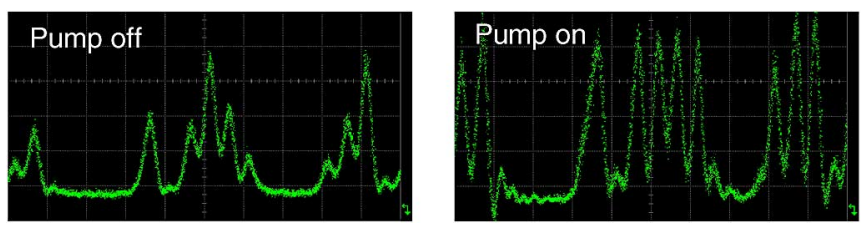

Fig. 6. RZ-OOK waveforms at the FOPA output with the pump turned OFF (left) and ON (right).

modulation from the signal to the pump is clearly visible for high input signal power and reflects the nature-pseudorandom versus periodic - of the power envelope of the signal.

The enhanced dynamic range is exploited to demonstrate amplitude regeneration of an RZ-DPSK signal. For this purpose, an extra MZM driven by a 10-GHz sinusoidal signal is used to emulate the intensity fluctuations that would result from transmission over an optical fiber link. The distorted signal is input to the FOPA with 13.4-dBm average power in order to experience gain saturation. The distorted input signal is shown in Fig. 5(a). This distortion results in $3.5-\mathrm{dB}$ penalty compared to a back-to-back undistorted RZ-DPSK signal and 4.1-dB penalty after propagation through the FOPA with the pump turned OFF. The optical waveform and the single-ended detected signal after demodulation (Fig. 5(c) and (b), respectively) clearly show severe intensity fluctuations. However, when the 30.5-dBm pump is turned ON, those amplitude fluctuations are suppressed [Fig. 5(d), (e)]. Accordingly, the penalty after the FOPA is reduced to $0.2 \mathrm{~dB}$, clearly demonstrating its regenerative behavior.

Amplitude equalization of RZ-OOK was also attempted with the same amount of intensity distortion and the same FOPA pump power. The waveforms at the FOPA output with the pump turned ON and OFF are shown in Fig. 6. The intensity of the signal was partly equalized owing to FOPA saturation for $13.2-\mathrm{dBm}$ input power. However, at this power level, the high SPM degradation prevented error-free detection of the signal, as anticipated from the input power tolerance investigation reported in Fig. 3 for an undistorted signal. For $10-\mathrm{dBm}$ average power, corresponding to the same peak power as for RZ-DPSK, only incomplete equalization was observed. Even though saturation may be obtained with lower pump and signal power, one important requirement for a practical amplitude regenerator is that it provides a sufficiently high output signal power and OSNR, which may not be met with conventional nonamplifying FWM configurations. The FOPA thus provides a unique combination of gain and saturation.

\section{CONCLUSION}

It has been shown that single-pump FOPAs offer an increased input power dynamic range for RZ-DPSK modulation compared to RZ-OOK. This behavior can be exploited to achieve intensity regeneration of RZ-DPSK signals in an FOPA with 22-dB gain, without being limited by SPM, as would be the case for RZ-OOK. The first unambiguous BER characterization of an FOPA-based regenerator for amplitude equalization of $40-\mathrm{Gb} / \mathrm{s}$ RZ-DPSK signals was also presented.

\section{REFERENCES}

[1] H. Kim and A. H. Gnauck, "Experimental investigation of the performance limitation of DPSK systems due to nonlinear phase noise," IEEE Photon. Technol. Lett., vol. 15, no. 2, pp. 320-322, Feb. 2003.

[2] M. Matsumoto, "Performance improvement of phase-shift-keying signal transmission by means of optical limiters using four-wave mixing in fibers," J. Lightw. Technol., vol. 23, no. 9, pp. 2696-2701, Sep. 2005.

[3] A. G. Striegler, M. Meissner, K. Cveček, K. Sponsel, G. Leuchs, and B. Schmauss, "NOLM-based RZ-DPSK signal regeneration," IEEE Photon. Technol. Lett., vol. 17, no. 3, pp. 639-641, Mar. 2005.

[4] K. Croussore and G. Li, "Amplitude regeneration of RZ-DPSK signals based on four-wave mixing in fibre," Electron. Lett., vol. 43, no. 3, pp. 177-178, Feb. 2007.

[5] K. Croussore and G. Li, "Phase and amplitude regeneration of differential phase-shift keyed signals using phase-sensitive amplification," IEEE J. Sel. Topics Quantum Electron., vol. 14, no. 3, pp. 648-658, May 2008.

[6] E. S. Awad, P. S. Cho, and J. Goldhar, "All-optical phase and amplitude regeneration of return-to-zero differential phase shift keying data," Opt. Lett., vol. 32, no. 4, pp. 352-354, Feb. 2007.

[7] K. Inoue, "Optical level equalisation based on gain saturation in fibre optical parametric amplifier," Electron. Lett., vol. 36, no. 12, pp. 1016-1017, Jun. 2000.

[8] M. Matsumoto, "Phase-preservation capability of all-optical amplitude regenerators using fiber nonlinearity," presented at the Optical Fiber Communication Conf. (OFC 2006), Anaheim, CA, Mar. 2006, Paper JThB18.

[9] M. Sköld, J. Yang, H. Sunnerud, M. Karlsson, S. Oda, and P. A. Andrekson, "Constellation diagram analysis of DPSK signal regeneration in a saturated parametric amplifier," Opt. Express, vol. 16, no. 9, pp. 5974-5982, Apr. 2008.

[10] C. Peucheret, M. Lorenzen, J. Seoane, D. Noordegraaf, C. Vandel Nielsen, L. Grüner-Nielsen, and K. Rottwitt, "Dynamic range enhancement and amplitude regeneration in single pump fibre optic parametric amplifiers using DPSK modulation," presented at the Eur. Conf. Optical Communication (ECOC 2008), Brussels, Belgium, Sep. 2008, Paper Tu.4.D.4.

[11] N. Alic, R. M. Jopson, J. Ren, E. Myslivets, R. Jiang, A. H. Gnauck, and S. Radic, "Impairments in deeply-saturated optical parametric amplifiers for amplitude- and phase-modulated signals," Opt. Express, vol. 15, no. 14, pp. 8997-9008, Jul. 2007. 